\title{
Giant pneumatization of sphenoid sinus: Report of four cases and review of literature
}

\author{
Neumatización gigante del seno esfenoidal: Reporte de cuatro casos y revisión de la literatura \\ Anne Marie Kusch 1,a;2,b, Vilma Ruiz García ${ }^{2, c, d}$
}

\section{RESUMEN}

El hueso esfenoidal ocupa la mayor parte de la zona anterior de la fosa craneal media, está compuesto por un cuerpo, dos pares de alas (mayores y menores) las que se proyectan lateralmente desde el cuerpo, y dos procesos pterigoideos proyectados inferior y lateralmente de las coanas. Este hueso representa el límite entre la fosa craneal anterior y media. Usualmente, el seno esfenoidal se encuentra ubicado en su cuerpo, el cual presenta una gran variación en su neumatización, variando desde ausente hasta extenso. Puede extenderse a distintas partes del hueso esfenoidal e inclusive a estructuras óseas cercanas. Su localización profunda hace difícil el diagnóstico mediante radiografías, especialmente cuando se utilizan técnicas convencionales. Se presentan cuatro casos de neumatización gigante del seno esfenoidal observados como hallazgo imagenológico.

PALABRAS CLAVE: Seno esfenoidal, variación anatómica, tomografía computarizada de haz cónico. (Fuente: DeCS BIREME).

\section{SUMMARY}

Sphenoid bone occupies most of the anterior part of the middle part of the skull base, it is compound by a body, two pair of wings (greater and lesser) which are laterally projected from the body and two pterygoid process projected inferiorly and laterally from choana. This bone represents the limit between the anterior and middle cranial fossa. Usually, the sphenoid sinus is located in the sphenoid body, and has a large variation in its pneumatization, ranging from absent to extensive. It is able to extent to different parts of the sphenoid bone or even to surrounding ones. The deep location makes difficult the radiographic diagnosis, especially when conventional radiographic techniques are used. Four cases of a giant pneumatization of the sphenoid sinus are presented observed as a radiological finding.

KEYWORDS: Sphenoid sinus, anatomic variation, recess, Cone-Beam Computed Tomography. (Source: MeSH NLM).

Universidad de los Andes. Santiago de Chile, Chile.

Departamento Radiología Bucal y Maxilofacial, Facultad de Estomatología, Universidad Peruana Cayetano Heredia. Lima, Perú.

a Cirujano Dentista;

b Residente Radiología Bucal y Maxilofacial;

c Magister Esp. Cirujano Dentista;

d Profesora 


\section{INTRODUCTION}

Sphenoid bone occupies most of the anterior part of the middle part of the skull base, it is compound by a body, two pair of wings (greater and lesser) which are laterally projected from the body and two pterygoid process projected inferiorly and laterally from choanae. All components have different and complex ossification centers (1). This bone represents the limit between the anterior and middle cranial fossa. Usually, the sphenoid sinus is located in sphenoid body; mainly characterized by being the most difficult paranasal sinus to access (2). It has a remarkable inter and intra-subject variations in terms of localization and shape. Most likely sphenoid sinus has the highest degree in variation regarding pneumatization, varying from absent to extensive (3). It is able to extend to different parts on the same sphenoid bone, like laterally to greater lesser wings, pterygoid plates or process, clinoid process and even posteriorly to the clivus; anterior clinoid process and pterygoid process pneumatization are amazingly common. It also can expand to other surrounding bones as occipital, palatine, vomer and ethmoid (4).

From a developmental point of view, this sinus has a primary pneumatization in the fourth intrauterine month, a secondary occurs from 2-3 years up 7 years accelerated then continues slowly until adolescent (5). Frequently it develops asymmetrically, resulting in an unequal pneumatization, and the intersinus septum, when is present, is deviated most of the times (6); leading to morphological variable shapes; which cannot be related to gender, age or race (7). Bolger et al (8), in the 90's studied the anatomic variations of paranasal sinuses and mucosal abnormalities, concluding that these morphological variations can predispose to chronic or recurrent sinusitis.
The aim of this article was to present four cases of giant pneumatization of sphenoid sinus observed as a radiological finding. They all attended to the Clínica Dental Docente de la Universidad Peruana Cayetano Heredia (Lima, Peru). They were ask to perform a Cone Beam Computed Tomography due to reasons that not concern this study, in where it was found a giant sphenoid sinus pneumatization. None of them presented clinical symptomatology related. Due to the fact that when presented an extensive pneumatization it causes a concomitant thickness and erosion of the sinus walls encouraging the exposure of adjoining cranial nerves or even vascular structures, and also can mimic pathologies. Anatomical variations can frequently be encountered; these should be considered and informed by the radiologist in order to prevent possible diagnostic errors.

\section{CASE REPORTS}

All patients come from the capital city, and the reason for consulting the Clínica Dental Docente de la Universidad Peruana Cayetano Heredia (Lima, Peru) is not related to the described finding.

\section{Case 1}

A 43 years old female patient. The image exam showed a large right pneumatization of sphenoidal sinus (figure $1(\mathrm{~A}, \mathrm{~B}, \mathrm{C})$ ).

\section{Case 2}

A 50 years old female patient. The image exam showed a large right pneumatization of sphenoidal sinus (figure $2(\mathrm{~A}, \mathrm{~B}, \mathrm{C})$ ).

\section{Case 3}

A 22 years old female patient. The images show a large left pneumatization of sphenoidal sinus (figure $3(\mathrm{~A}, \mathrm{~B}, \mathrm{C}))$.
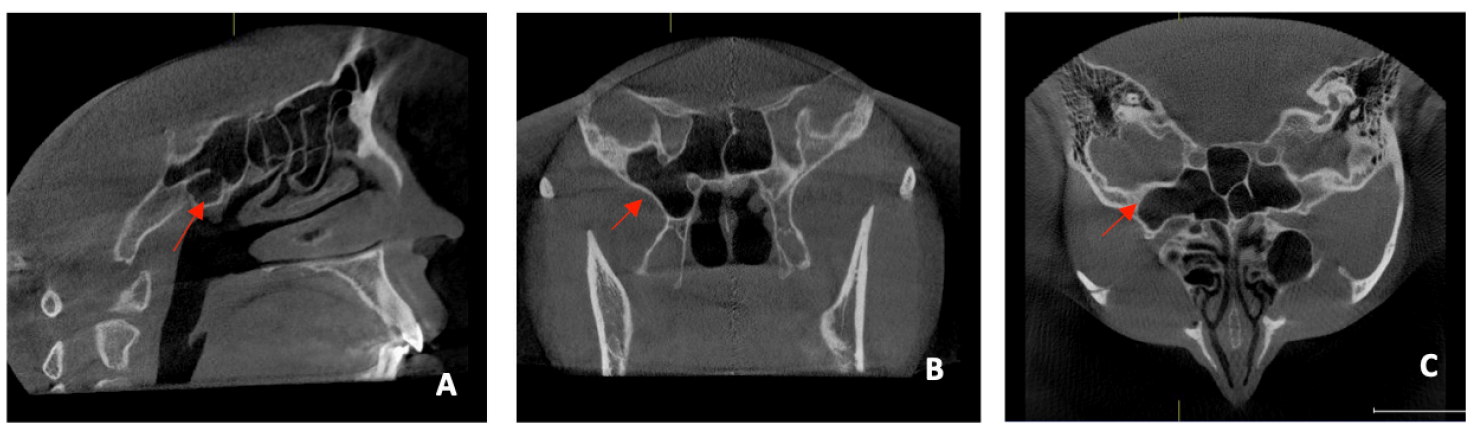

Figure 1. A. Sagital view: pneumatization of the sphenoid sinus extending laterally and it can be seen the pneumatization of the ethmoid cells. B. Coronal view: the lateral recess reaches the pterygoid process. C. Axial view: pneumatization of mastoid cells, lateral recess on the right side and in the left sphenoid sinus it is shown more than one septum and an incomplete septum. 

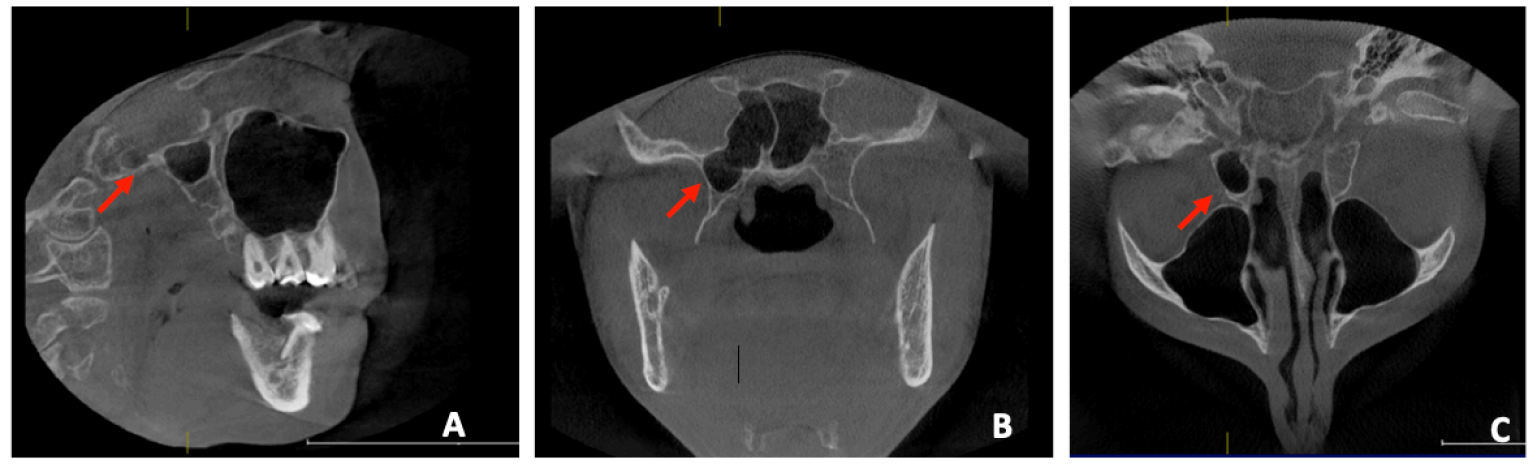

Figure. 2. A. Sagital view: pneumatization of the sphenoid sinus extending laterally. B. Coronal view: the lateral recess reaches near the pterygoid process. C. Axial view: pneumatization of mastoid cells, lateral recess on the right side.
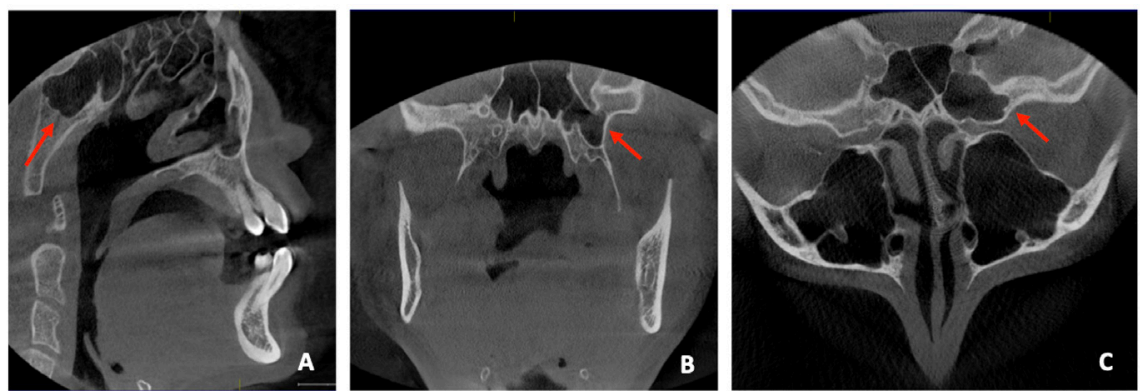

Figure 3. A. Sagital view: pneumatization of the sphenoid sinus extending laterally and pneumatization of ethmoid cells. B. Coronal view: presence of incomplete septum on the right side and, on the left side the lateral recess reaches near the pterygoid process.

C. Axial view, presence of a complete septum and lateral recess on the left side.
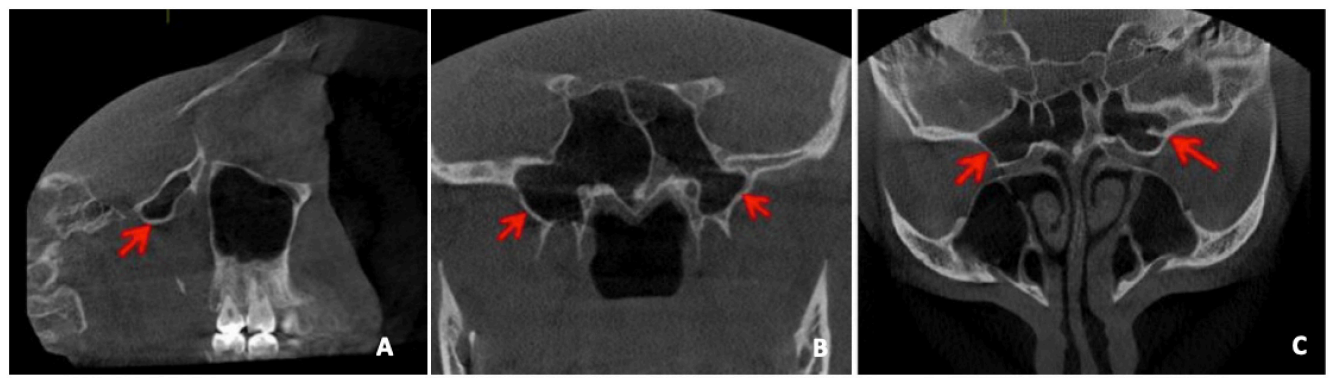

Figure 4. A. Sagital view: pneumatization of the sphenoid sinus extending laterally. B. Coronal view: pneumatization on both sides, being the right one more extensive reaching the pterygoid process, on the left side reaches only near it. C. Axial view, presence of two incomplete septum on the right sphenoid sinus and one on the left side.

\section{Case 4}

A 28 years old male patient. The images show a large pneumatization on both sides of sphenoidal sinus, predominating the right side (figure $4(\mathrm{~A}, \mathrm{~B}, \mathrm{C})$ ).

\section{DISCUSSION}

A wide range of normal variations can present in sphenoid sinus pneumatization regarding size, shape and septation (1). This sinus is located in the center of cranial base, encircled by vital neurovascular structures such as pituitary fossa and planum sphenoidal located superiorly, choana inferiorly, cavernous sinuses laterally and ethmoidal air cells anteriorly (3), and various vital anatomical structures such as: internal carotid arteries, optic nerve, III, IV and VI cranial nerves, cavernous sinus, basilar sinus and brain stem (9). So, its morphological variations may affect its relations to these structures specially with the internal carotid artery, optic nerve, cavernous 
sinus and pituitary gland being able to produce bony prominences and even recesses inside the sinus (10); mimic diseases and even misdiagnose pathological conditions (11).

Normally this condition does not require any treatment (12). When an excessive pneumatization presents usually it does with a concomitant thickness, demineralization and erosion of the sinus walls making more prone to vidian, maxillary and optic nerves and internal carotid arteries exposure. Also, can mimic tumoral lesion, usually a meningioma $(7,13,20)$. The consequent protrusion or dehiscence of near vascular and neural structures are relativity frequent $(7,13,14)$. This information is not newly acquired, Sennaroglu et al (15), in 1995 already reported cases in which swelling, and eye proptosis was caused by an excessive pneumatization.

As several organs and structures composing our body, the sphenoid sinus as we get older undergoes further enlargement with a consequent thinning and even absorption of its bony walls (12).

The deep location makes difficult the radiographic diagnosis, especially when conventional radiographic techniques are used. Radiographically it can be seen in three ways: 1) radiolucent image superimposed on a part of the zygomatic arch, 2) similar to a cystic lesion (loculated image) and 3) image similar to the pterygomaxillary fissure (9). As the four presented cases, most sphenoid sinus pneumatization's are discovered incidentally on daily imaging exams, often due to the lack of symptoms.

Currently two main classifications of sphenoid sinus pneumatization are used according its sagittal extension and relation to sella turcica, the one first described by Congdon in 1920, but widely diffused by Hammer and Radberg in 1961 into three types (11): 1) conchal: pneumatization is absent or minimal; 2) presellar: pneumatization reaches the anterior wall of the sella; and 3) sellar: pneumatization extends behind sella turcica's anterior wall. And another one in which the author included the postsellar type in which the pneumatization extends beyond the sellar indentation (1). A more recent classification was presented in 2010 by Wang et al., this includes types of lateral recess, they described this recess as the presence of lateral air cells extending laterally between the vidian canal and the rotundum foramen, beyond the sphenoid body into the greater wing and/or the pterygoid process (3). They proposed a classification into five types according its anatomic extension: A) Body: pneumatization is constrain to the sphenoid body; B) Lesser wing: pneumatization goes through the optic strut and into the anterior clinoid process; C-E) Lateral: the lateral wall reaches beyond the separation between the sphenoid body an lateral parts (VR line) crossing the middle the medial edge of foramen rotundum and vidian canal; C) Greater wing: pneumatization extends between the foramen rotundum and vidian canal into greater wing; D) Pterygoid: pneumatization reaches the pterygoid process going through foramen rotundum and vidian canal; and E) Full lateral: sinus extends laterally into both greater wings and pterygoid process.

Being widely use the Congdon (16) classification, several studies had found that the sellar type is the most prevalent pneumatization, follow by the presellar type and being the conchal type the least common $(5,17)$. Agreeing with this classification, we observed the sellar type as the most frequent type of pneumatization (presented in all cases), followed by the presellar type (case 1 and 3), being less prevalent the conchal type (case 4 on the right side). Applying Lang's classification (18), we can categorize the pneumatization presented on the four cases as postsellar. Which has a prevalence reported on literature between $12-50 \%(3,7)$. More rarely we found, on the three cases, the extension in the lateral part, which is less frequent than in the anterior part where exists a fusion barrier between the lingula and greater wing (19). Base on Wang's sphenoid sinus lateral recess classification we can state that the first and fourth case presents a type E and the second and third one presents a type $\mathrm{D}$; this author showed a prevalence of this type of pneumatization of $77 \%$ (3). Contrary to the most often published, we found the lateral recess on the right side in three cases (1,2 and 4) (3). One case published shows a case where this recess presents in both sides (5) like our case number 4.

We cannot associate the radiological finding of this pneumatization to age, gender or even race, because this has not been established yet $(7,20)$.

Hammer and Radberg, presented the possible septum types: medial or main, intersinus, sagittal lateral and/or frontal lateral, there is also the possibility of absent (15). More often it is seen the presence of multiple septum as it was found on most of our cases creating more than one compartment. The main septum it is located in the midline but usually deviated to one side, making an asymmetrical appearance of the sella turcica floor (20). We could also notice the 
presence of an incomplete septum in three cases $(1,3$ and 4), this feature has a low prevalence published on literature $(6,15)$. This characteristic could be explain in the fact of the Peruvian population is predominantly half blood, and there is not a specific patron.

In conclusion, during imaging exams there are high possibilities to find anatomic variations, these should be reported by radiologist; not only to guide the clinician but to avoid misdiagnosis; and to orientate surgeons in oden of planning procedures.

\section{Declaración de conflictos de interés:}

Sin conflictos de interés.

\section{Correspondencia:}

Anne Marie Kusch

Correo electrónico: anne.kusch@upch.pe

\section{REFERENCES}

1. Drake R, Vogl AW, Mitchell AWM. Gray's Anatomy for Students. 3th Ed. London: Elsevier Health Sciences; 2014.

2. Cappabianca P, Cavallo LM, Colao A, et al. Endoscopic endonasal transsphenoidal approach: outcome analysis of 100 consecutive procedures. Minim Invasive Neurosurg. 2002; 45:193-200.

3. Wang J, Bidari $\mathrm{S}$, Inoue $\mathrm{K}$, Yang $\mathrm{H}$, Rhoton $\mathrm{A}$. Extensions of the sphenoid sinus: a new classification. Neurosurgery. 2010; 66(4):797-816.

4. Turkdogan FT, Turkdogan KA, Dogan M, Atalar $\mathrm{MH}$. Assessment of sphenoid sinus related anatomic variations with computed tomography. Pan Afr Med J. 2017; 27:109.

5. Baldea V, Sandu OE. CT study of the sphenoid sinus pneumatization types. Romanian Journal of Rhinology. 2012; 2(5):17-30.

6. Kashyap SK, Purohit JP, Selvaraj S, et al. Anatomical variations of sphenoidal inter-sinus septa in terms of number and attachments - a CT finding. J Evolution Med Dent Sci. 2017; 6(12):955-9.

7. Tomovic S, Esmaeili A, Chan NJ, et al. HighResolution Computed Tomography Analysis of Variations of the Sphenoid Sinus. J Neurol Surg B Skull Base. 2013; 74(2):82-90.

8. Bolger WE, Butzin CA, Parsons DS. Paranasal sinus bony anatomic variations and mucosal abnormalities: CT analysis for endoscopic sinus surgery. Laryngoscope. 1991; 101(1):56-64.

9. 9. Oliveira JMM, Alonso MBCC, de Sousa E, et al. Volumetric study of sphenoid sinuses: anatomical analysis in helical computed tomography. Surg Radiol Anat. 2017; 39(4):367-74.
10. Dal Secchi M, Dolci R, Teixeira R, Lazarini P. An analysis of anatomic variations of the sphenoid sinus and its relationship to the internal carotid artery. Int Arch Otorhinolaryngol. 2018; 22(2):161-6.

11. Hamberger C, Hammer G, Norlen G. Transphenoidal hypophysectomy. Arch Otol. 1961; 74:2-8.

12. Idowu OE, Balogun BO, Okoli CA. Dimensions, septation, and pattern of pneumatization of the sphenoidal sinus. Folia Morphol (Warsz). 2009; 68(4):228-32.

13. Liang H, Benson BW, Frederiksen NL. Pneumatization of the pterygoid process of the sphenoid bone. Dentomaxillofac Radiol. 2001; 30(1):63.

14. Unal B, Bademci G, Bilgili YK, Batay F, Avci E. Risky anatomic variations of sphenoid sinus for surgery. Surg Radiol Anat. 2006; 28(2):195-201.

15. Sennaroglu L, Ayas K, Bayar N, Hosal S. Giant sphenoid sinus. A case report. Rhinology. 1995; 33(1):52-3.

16. Congdon ED. The distribution and mode of origin of septa and walls of the sphenoid sinus. The Anatomical Record. 1920; 18(2):97-123.

17. Craiu C, Sandulescu M, Rusu MC. Variations of sphenoid pneumatization: a CBCT study. Romanian Journal of Rhinology. 2015; 5(18):107-13.

18. Croft C. Clinical anatomy of the nose, nasal cavity, and paranasal sinuses. Clinical Otolaryingology. 1991; 16(4):430-430.

19. Cope VZ. The internal structure of the sphenoidal sinus. J Anat. 1917; 51(2):127-36.

20. Aburto A, Valenzuela S, Yáñez A, Lemp M, Sanhueza A, Olivares P. Radiologic anatomy of Sphenoidal sinus, analysis of 120 surgically intervened patients. Rev Chil Neurocirugia. 2015; 41:54-8.

Recibido: 05/10/2018

Aceptado: 29/12/2018 